\title{
Evaluation of metallurgical behavior of oxygen and sulfur in base iron for ductile iron production based on thermal analysis
}

\author{
D. Li*, Z. Xu, X. Ma, D. Shi, C. Han, L. Wang \\ School of Materials Science \& Engineering, Harbin University of Science and Technology, Harbin 150040, P. R. China
}

Received 8 May 2019, received in revised form 3 July 2019, accepted 9 July 2019

\begin{abstract}
Oxygen and sulfur have an important influence on nodularization during ductile iron preparation. In this paper, the metallurgical behavior of oxygen and sulfur for nodularization were studied by thermal analysis with Al-contained sample cup. The results show that oxygen has a significant influence on both primary phase and eutectic solidification of base iron because of its greater chemical affinity with carbon and silicon. The morphology and status of oxidized products obtained during nodularization affect eutectic graphite crystallization while sulfur with less electron affinity affects eutectic graphite nucleation and growth by combining sulfides as aided nucleation substrate. After nodularization, the formation and aggregation of sulfide particles are relatively slow in iron liquid. The dispersive deoxidization and desulfurization composites suspending in iron melt may be the beneficial core of spherical graphite. From the view of thermodynamics and kinetics, the direct anti-spherification action of sulfur is always weaker than that of oxygen.
\end{abstract}

K e y w o r d s: ductile iron, oxygen and sulfur, metallurgical characteristics, thermal analysis, experimental study

\section{Introduction}

Ductile iron has been widely used in modern mechanical equipment because of its excellent mechanical properties, low production cost, and convenient manufacture [1-4]. The variety of application and production conditions make it an urgent problem to control the production process of ductile iron [5-9]. The addition amount of nodulizer is closely related to the metallurgy state of base iron. Therefore, calculating the amount of nodulizer accurately according to the state of base iron is an important research subject concerned by the foundry workers $[10,11]$.

Oxygen and sulfur are generally accepted as the anti-spherification elements, but a base iron without oxygen and sulfur is not in its optimal state. Appropriate oxygen and sulfur content plays a key role in graphite nucleus and inhibits the decline of nodularizing effect. Peroxidation or high sulfur content molten iron cannot make the molten iron normal nodularization treatment, such as yesterday's base iron. For effective control of nodularization, it is very important to develop an effective method to detect the oxygen and sulfur content and their metallurgical behavior in the iron melt and clarify the mechanism and characteristics of the two anti-spherification elements. At present, the concentration difference battery method is an effective means for determining the active oxygen and sulfur content in iron melt [12-17]. However, the true value of the active oxygen or sulfur in the iron melt cannot be obtained. Besides, according to the Nernst equation, the calculated oxygen or sulfur activity value using the concentration difference battery method is strongly dependent on temperature change. The method is thus in lack of reliability and comparability [12]. Casting thermal analysis is an effective method that can sensitively indicate the solidification characteristics of iron melt [18-21]. The research on the metallurgical properties of cast iron shows when the $\mathrm{Al}$ content in the iron melt is less than $1 \mathrm{wt} . \%$, $\mathrm{Al}$ has scarcely any influence on the cooling process and as-casting structure of the iron melt. In this case, Al mainly acts as de-oxygenation in molten iron [22, $23]$. On this basis, de-oxygenation sample cups with a

*Corresponding author: e-mail address: dyli@hrbust.edu.cn 
Table 1. Chemical composition of the base irons used in experiments, (wt.\%)

\begin{tabular}{lcccccc}
\hline Base iron NO. & $\mathrm{C}$ & $\mathrm{Si}$ & $\mathrm{Mn}$ & $\mathrm{P}$ & $\mathrm{S}$ & $\mathrm{CE}^{*}$ \\
\hline Base metal & $3.60-3.75$ & $1.45-1.55$ & $0.3-0.5$ & $\leq 0.05$ & $\leq 0.03$ & $4.10-4.30$ \\
Iron ingot & 3.68 & 1.48 & 0.42 & 0.038 & 0.026 & 4.18 \\
\hline
\end{tabular}

${ }^{*} \mathrm{CE}=\mathrm{C} \%+(\mathrm{Si} \%+\mathrm{P} \%) / 3$

continuously variable amount of active $\mathrm{Al}$ contained additive were designed, and the effect of oxygen \& sulfur content and their metallurgical behavior were deeply studied. The results can provide experimental data reference for the precise addition of nodulizer.

\section{Experimental procedures}

To ensure the consistency of the chemical composition of base iron in different testing furnaces, $100 \mathrm{~kg}$ base metal liquid was melted at one time in the medium-frequency induction furnace in advance. After proper overheat, it was poured into small iron ingots for use in the following tests. The chemical compositions for iron melt and ingot are shown in Table 1, respectively. Furnace charge includes pig iron, $45^{\#}$ steel, low aluminum $75 \mathrm{SiFe}$ alloy, and medium Mn alloy.

For oxygen metallurgy testing experiment, $30 \mathrm{~kg}$ medium frequency induction furnace (acidic lining, $2.4 \mathrm{kHz}$ ) was used to melt $20 \mathrm{~kg}$ iron ingot, and the corresponding amount of $\mathrm{Fe}_{2} \mathrm{O}_{3}$ chemical reagent was added accordingly to increase oxygen treatment. There are two kinds of cups added with $\mathrm{Fe}_{2} \mathrm{O}_{3}, 0.047$ and $0.094 \%$, respectively, as in Table 2 . The main basis for adding amount is that the residual $\mathrm{Mg}$ in ductile iron melt ranges from 0.025 to $0.060 \%$. Therefore, the addition amount of $\mathrm{Fe}_{2} \mathrm{O}_{3}$ is set to consume $0.025 \%$ $\mathrm{Mg}$ according to the stoichiometric ratio and considering the reaction effect, so that graphite in molten iron cannot precipitate in spherical form. After holding at $1450^{\circ} \mathrm{C}$ for $10 \mathrm{~min}$ and drossing, the molten iron was taken to pour an empty cup, and different $\mathrm{Al}$ contained thermal analysis sample cups continuously. After the test, the temperature of the base iron was held statically with low power. The molten iron was poured out when the temperature dropped to $1420^{\circ} \mathrm{C}$ (at the rate of $\left.2-3^{\circ} \mathrm{C} \min ^{-1}\right)$.

A kind of specialized dry clay sample cup $\left(\varnothing 30 \times 50 \mathrm{~mm}^{2}\right.$ cavity, $5 \mathrm{~mm}$ wall thickness) was used for thermal analysis, surrounded with a steel casing of $3 \mathrm{~mm}$ thick to increase the intensity of sample cup at high pouring temperature. A ceramic fiber sampling spoon was preheated to $550^{\circ} \mathrm{C}$ and used to take sufficient molten iron for pouring the testing sample cups, spectrum chilling specimen and wedge specimen (specification: $25 \times 50 \times 150 \mathrm{~mm}^{3}$ ) in turn. It took about $10 \mathrm{~s}$ from sampling the molten iron in a furnace to initially pouring sample. Each pouring took about $2-3 \mathrm{~s}$.

\section{Results and discussion}

\subsection{Evaluation of metallurgical behavior of oxygen}

Figure 1 shows the de-oxygenation cooling curve of molten iron with different oxidation degrees, and characteristic temperatures are shown in Table 2. As shown in Fig. 2, change of the active $\mathrm{Al}$ contained additives (indicating de-oxygenation degree) in sample cup has a significant influence on the liquidus temperature $T_{\mathrm{L}}$ and the slope angle $\alpha_{\mathrm{L}}$ of the liquidus platform at the initial crystallization stage before eutectic solidification. Figure 1(a) shows that the $T_{\mathrm{L}}$ decreases with further de-oxygenation by active $\mathrm{Al}$ content increase. As the proportion of active $\mathrm{Al}$ increases, the $T_{\mathrm{L}}$ decreases significantly when the addition amount is less than $0.09 \%$, and the $T_{\mathrm{L}}$ tends to be a relatively stable level within $0.12-0.15 \%$ for active $\mathrm{Al}$ dosage in the sample cup. Because $T_{\mathrm{L}}$ rises about $12{ }^{\circ} \mathrm{C}$ per every $0.1 \%$ reduction of liquidus carbon equivalent CEL, the fluctuation amplitude of CEL of the base iron in experiments can reach $0.075-0.167 \%$. The more seriously the molten iron is oxidized, the greater is the inhibition on the activity of carbon atom by oxygen, and the higher the $T_{\mathrm{L}}$ would rise. Moreover, when the molten iron is oxidized to a certain degree, the effect of increasing oxygen would be reduced by further adding $\mathrm{Fe}_{2} \mathrm{O}_{3}$. The de-oxygenation function of more than $0.12 \% \mathrm{Al}$ additives in the sample cup can always reduce the oxygen content to a stable level. As shown in Fig. 2b, the degree of de-oxygenation by the active $\mathrm{Al}$ in the sample cup also has a significant influence on $\alpha_{\mathrm{L}}$. As the de-oxygenation degree increases in the sample cup, there is a maximum value of $\alpha_{\mathrm{L}}$ under various oxidization degrees. This phenomenon indicates when the de-oxygenation process develops to a certain degree, the crystallization of primary austenite becomes difficult, and the latent heat released by austenite crystallizing decreases, resulting in a sudden increase in the $\alpha_{\mathrm{L}}$ value. Moreover, the more severe the molten iron is oxidized, the higher is the $\alpha_{\mathrm{L}}$ value and the maximum value moves toward the lower de-oxygenation state, which makes the mutation phenomenon of $\alpha_{\mathrm{L}}$ value in changing curve more signif- 
Table 2. Characteristic temperatures in cooling curves of base iron treated with oxygen and sulfur

\begin{tabular}{|c|c|c|c|c|c|c|c|}
\hline \multirow{2}{*}{\multicolumn{2}{|c|}{ Base iron state }} & \multicolumn{2}{|c|}{ Initial crystallization phase } & \multicolumn{4}{|c|}{ Eutectic solidification phase } \\
\hline & & $\begin{array}{c}\text { Liquidus } \\
\text { temperature, } \\
T_{\mathrm{L}}\left({ }^{\circ} \mathrm{C}\right)\end{array}$ & $\begin{array}{c}\text { Liquidus } \\
\text { platform } \\
\text { slope angle, } \\
\alpha_{\mathrm{L}}\left({ }^{\circ} \mathrm{C} \mathrm{s}^{-1}\right)\end{array}$ & $\begin{array}{c}\text { Lowest } \\
\text { eutectic } \\
\text { temperature, } \\
T_{\mathrm{EU}}\left({ }^{\circ} \mathrm{C}\right)\end{array}$ & $\begin{array}{l}\text { Recalescence } \\
\text { temperature, } \\
\qquad R\left({ }^{\circ} \mathrm{C}\right)\end{array}$ & $\begin{array}{l}\text { Eutectic } \\
\text { time, } \\
t_{\mathrm{E}}(\mathrm{s})\end{array}$ & $\begin{array}{l}\text { Oxidation } \\
\text { factor, } \\
\text { OXF (\%) }\end{array}$ \\
\hline \multirow{6}{*}{ Base metal melt } & untreated & 1179.1 & 0.43 & 1141.6 & 4.7 & 88.6 & 26.0 \\
\hline & $0.03 \% \mathrm{Al}$ & 1175.8 & 0.45 & 1142.3 & 3.8 & 87.5 & 24.2 \\
\hline & $0.06 \% \mathrm{Al}$ & 1173.6 & 0.54 & 1143.8 & 2.8 & 81.2 & 18.5 \\
\hline & $0.09 \% \mathrm{Al}$ & 1171.7 & 0.72 & 1141.9 & 2.5 & 78.4 & 14.7 \\
\hline & $0.12 \% \mathrm{Al}$ & 1170.2 & 0.70 & 1141.1 & 3.7 & 88.0 & 16.5 \\
\hline & $0.15 \% \mathrm{Al}$ & 1170.1 & 0.64 & 1140.3 & 3.1 & 91.7 & 11.2 \\
\hline \multirow{6}{*}{$\begin{array}{l}\text { Iron ingot melt } \\
\text { treated with } \\
0.047 \% \mathrm{Fe}_{2} \mathrm{O}_{3}\end{array}$} & untreated & 1186.8 & 0.70 & 1141.3 & 3.6 & 77.2 & 32.2 \\
\hline & $0.03 \% \mathrm{Al}$ & 1180.5 & 0.75 & 1141.7 & 2.8 & 78.4 & 29.8 \\
\hline & $0.06 \% \mathrm{Al}$ & 1175.6 & 0.85 & 1142.6 & 2.5 & 85.8 & 27.6 \\
\hline & $0.09 \% \mathrm{Al}$ & 1172.3 & 1.07 & 1143.5 & 2.5 & 81.2 & 27.8 \\
\hline & $0.12 \% \mathrm{Al}$ & 1170.8 & 0.71 & 1142.2 & 2.5 & 80.5 & 21.5 \\
\hline & $0.15 \% \mathrm{Al}$ & 1170.5 & 0.68 & 1141.2 & 2.4 & 78.6 & 21.3 \\
\hline \multirow{6}{*}{$\begin{array}{l}\text { Iron ingot melt } \\
\text { treated with } \\
0.094 \% \mathrm{Fe}_{2} \mathrm{O}_{3}\end{array}$} & untreated & 1190.8 & 1.13 & 1141.2 & 2.7 & 72.6 & 35.7 \\
\hline & $0.03 \% \mathrm{Al}$ & 1183.4 & 1.20 & 1141.3 & 2.6 & 76.5 & 32.6 \\
\hline & $0.06 \% \mathrm{Al}$ & 1178.1 & 1.30 & 1141.3 & 2.8 & 75.7 & 30.3 \\
\hline & $0.09 \% \mathrm{Al}$ & 1172.2 & 1.11 & 1142.3 & 2.5 & 71.2 & 28.6 \\
\hline & $0.12 \% \mathrm{Al}$ & 1170.3 & 0.84 & 1140.4 & 2.7 & 70.2 & 24.4 \\
\hline & $0.15 \% \mathrm{Al}$ & 1170.2 & 0.76 & 1140.0 & 2.1 & 70.4 & 23.8 \\
\hline \multirow{3}{*}{$\begin{array}{l}\text { Iron ingot } \\
\text { melt treated } \\
\text { with } 0.077 \% \mathrm{FeS}\end{array}$} & untreated & 1179.0 & 0.42 & 1142.4 & 5.1 & 91.5 & 27.5 \\
\hline & $0.06 \% \mathrm{Al}$ & 1173.4 & 0.51 & 1145.1 & 3.6 & 99.6 & 25.3 \\
\hline & $0.12 \% \mathrm{Al}$ & 1170.5 & 0.71 & 1142.8 & 3.4 & 92.3 & 14.8 \\
\hline \multirow{3}{*}{$\begin{array}{l}\text { Iron ingot melt } \\
\text { treated with } \\
0.154 \% \mathrm{FeS}\end{array}$} & untreated & 1179.1 & 0.45 & 1142.8 & 4.8 & 92.6 & 26.8 \\
\hline & $0.06 \% \mathrm{Al}$ & 1173.3 & 0.53 & 1145.3 & 3.5 & 102.4 & 25.7 \\
\hline & $0.12 \% \mathrm{Al}$ & 1170.2 & 0.72 & 1143.5 & 3.2 & 97.5 & 15.1 \\
\hline
\end{tabular}

icant. Changing the carbon equivalent of the molten iron, the maximum value of $\alpha_{\mathrm{L}}$ stayed in the scope of $0.5-0.8^{\circ} \mathrm{C} \mathrm{s}^{-1}$ in experiments. Further study found that as the carbon equivalent increases, especially the carbon content, the $\alpha_{\mathrm{L}}$ value decreases, and the maximum point moves to a lower de-oxygenation state.
This demonstrates when holding in the range of theoretical de-oxygenation temperature $T_{\text {eq }}$ and actual boiling temperature $T_{\mathrm{B}}$ of $\mathrm{CO}$ gas by carbon oxidation in molten iron, although the reaction between oxygen and silicon still can be carried out, their chemical potential energy becomes smaller, and the constraint 

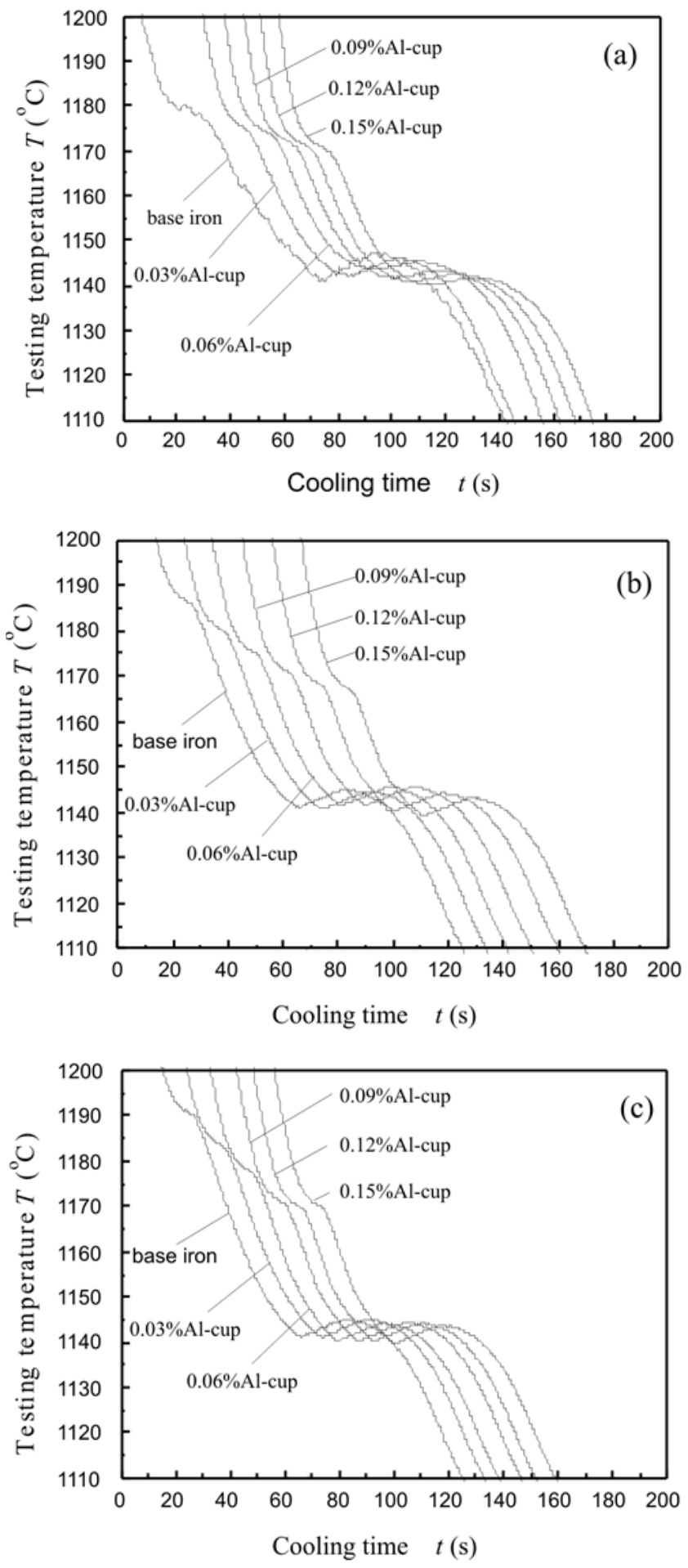

Fig. 1. Cooling curves of oxygen characteristic for base iron melt.

effect on oxygen atom by silicon atom is weakened. Moreover, it is difficult for $\mathrm{CO}$ gas product escaping from molten iron, resulting in a slow chemical reaction rate, but the effect of carbon to restrain oxygen behavior is increasing gradually. Also, when carbon

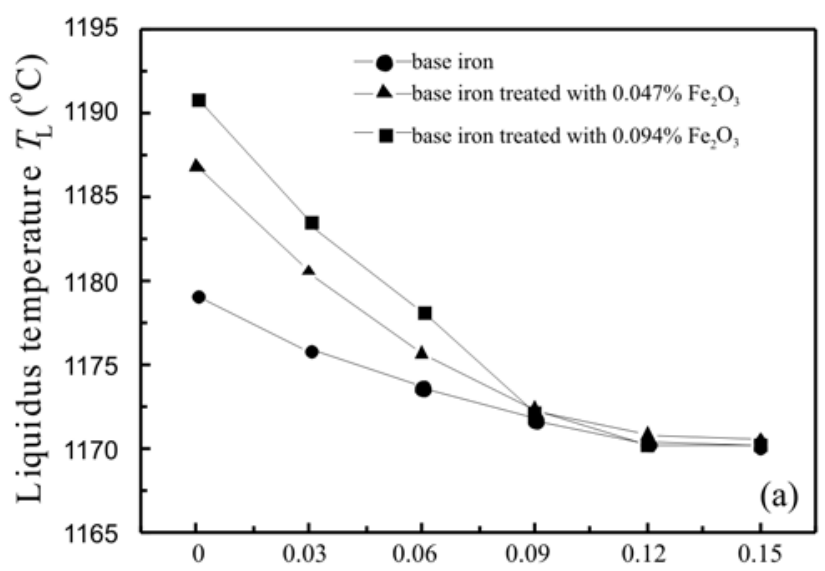

Amount of $\mathrm{Al}$ contained in sample cup (\%)

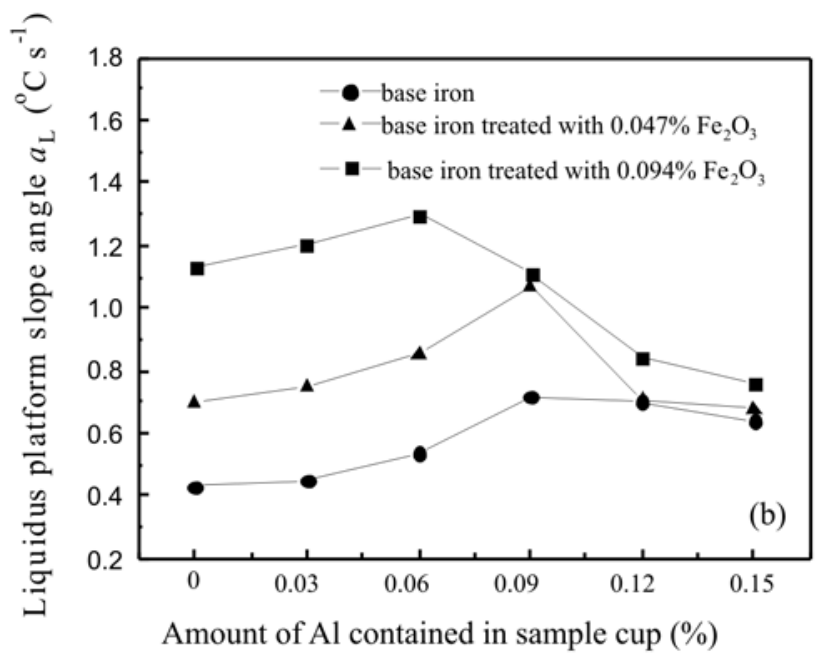

Fig. 2. Changes of characteristic temperatures in the initial phase with the deoxidized degree for the different oxidizing degree iron melt.

is increasing, the binding trend between carbon and oxygen is strengthened. This further indicates that for ductile iron that requires high carbon content, the increase of carbon content in base iron leads to enhancement of the metallurgy effect controlled by oxygen. Consequently, the effect of oxygen content on eutectic precipitation of spheroidal graphite is increased. Therefore, the study of oxygen behavior characteristics in graphite morphology control is particularly important.

As shown in Table 2, oxygenation and de-oxygenation treatments have significant effects on eutectic characteristic parameters in experiments. It can be seen from Fig. 3a that $T_{\mathrm{EU}}$ changes significantly with a different de-oxygenation degree. A maximum value of $T_{\mathrm{EU}}$ appears in the range from the original state of molten iron to the stable state of de-oxidization. Moreover, with the increase of oxidation degree of base iron, $T_{\mathrm{EU}}$ value decreases, and the maximum value 

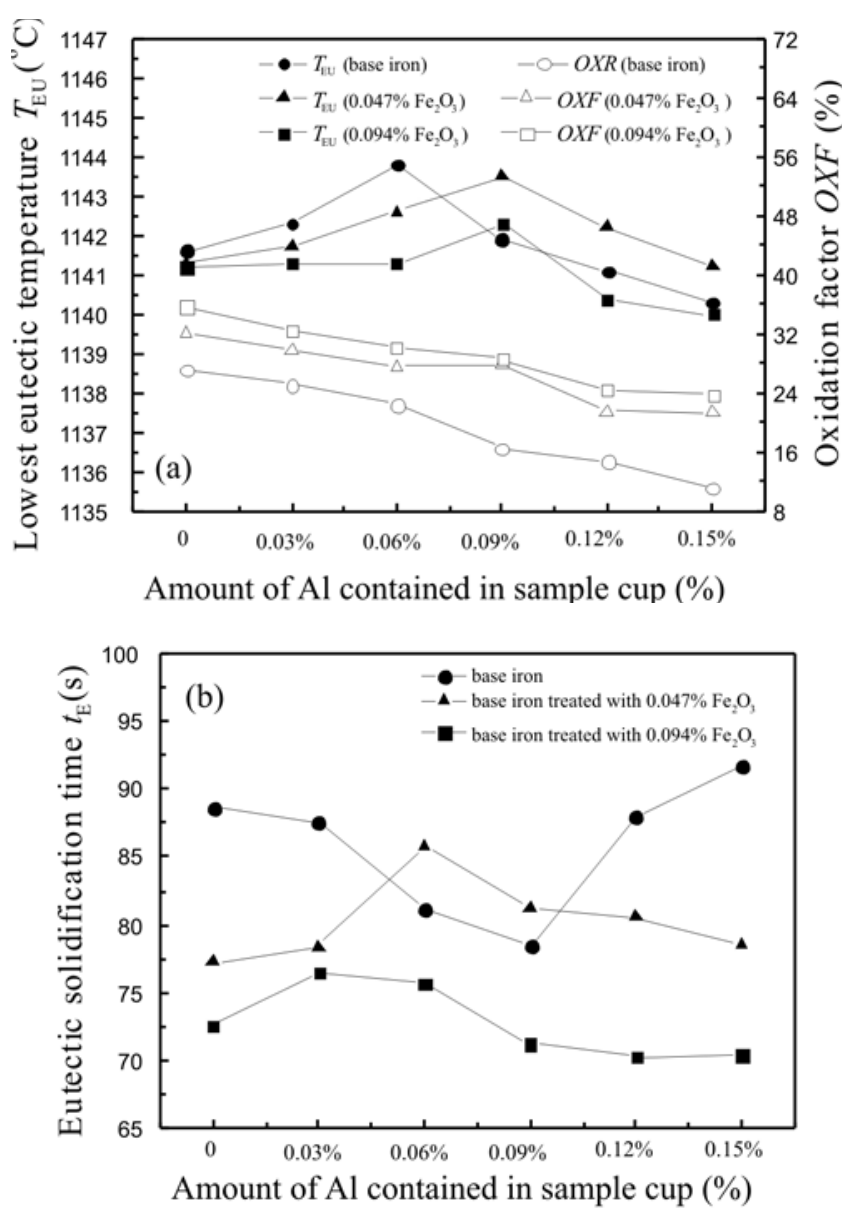

Fig. 3. Change of eutectic characteristic values with different oxidization degree.

about $T_{\mathrm{EU}}$ moves to the low-oxidation degree state. The eutectic recalescence temperature $R$ has the same variation trend, but not as obvious as $T_{\mathrm{EU}}$. Oxidation factor $(\mathrm{OXF})$ is defined as the ratio of the solidifying latent heat of eutectic recalescence precipitation phase to that of the total eutectic precipitation phase. This OXF value indicates the proportion of graphite precipitation in the first half of eutectic to the total amount of graphite. It can clearly show the effect of the degree of oxidation on the nucleation state of graphite eutectic. A small OXF value indicates a poor initial nucleation state of base iron and less graphite matrix.

On the contrary, an overly high OXF value presents that a high content of oxygen has been introduced in the base iron. In this situation, the initial austenite volume increases. As shown in Fig. 3a, OXF value tends to increase with the rise of oxidation degree of base iron. Accordingly, OXF value decreases as deoxidization was carried out by active $\mathrm{Al}$ additives in the sample cup. However, the de-oxygenation degree is limited for severely oxidized base iron. From the perspective of graphitization, the base iron should have a high content of active oxygen and a moderate degree of oxidation; excessive oxidation forms more $\mathrm{FeO}$, which is not conducive to the graphite nucleation.

As can be seen in Fig. 3b, de-oxygenation by active $\mathrm{Al}$ additives in the sample cup has a significant effect on the eutectic solidification of graphite precipitation. When the degree of oxidation of base iron is low, the eutectic reaction enduring time $t_{\mathrm{E}}$ in the cooling curve decreases first and then increases with the degree of de-oxidation. According to the de-oxygenation nucleation theory, moderate de-oxygenation for the molten iron makes the potential energy of the eutectic graphite nucleation increase. The accelerating development of the eutectic reaction leads to rapid solidification. When the molten iron is completely deoxidized, oxygen content reaches a very low level. In this case, although graphite cannot precipitate as nodular, the tendency of spheroidizing growth is strengthened, and the solidification mode tends to be mushy. At this moment, the potential energy of the graphite nucleation is relatively poor, leading to slow precipitation of graphite. Thus, a relatively small released heat brings about a less eutectic recalescence temperature $R$ and prolonged eutectic reaction time $t_{\mathrm{E}}$. When a high oxidation degree is introduced in molten iron, the de-oxygenation products lose the nucleation function for graphite, leading to an increase of under-cooling degree. As a result, the molten iron tends to solidify as white fracture, the eutectic temperature rises slightly after nucleation, and the eutectic enduring time $t_{\mathrm{E}}$ becomes shorter. De-oxygenation treatment takes care of the situation, contributing to the increase of $t_{\mathrm{E}}$. However, the increase of $t_{\mathrm{E}}$ in the highly oxidized molten iron is limited, and the graphitization performance is difficult to recover. Therefore, only a moderate oxidation degree of molten iron can ensure an optimal nucleation and growth conditions of eutectic solidification. There is the same changing trend of the curve when the contents of carbon and silicon change, but the optimal nucleation state of high carbon equivalent molten iron develops to low de-oxygenation state. Nodularization and inoculation are a de-oxygenation process, as well as a process of formation for spherical graphite nucleation matrix. Due to the solidification mode of ductile iron is divorced eutectic, it needs more graphite cores than gray iron to maintain this difficult precipitation condition.

\subsection{Evaluation of metallurgical behavior of sulfur}

Figure 4 shows the de-oxygenation cooling curve of molten iron treated with different $\mathrm{FeS}$ addition to increase sulfur, tested in null $\mathrm{Al}$ added, $0.06 \% \mathrm{Al}$ and $0.12 \% \mathrm{Al}$ contained sample cups, including $0.077 \%$ FeS and $0.154 \% \mathrm{FeS}$ treated base iron for ductile iron. The characteristic temperatures are shown in Table 2.

It can be seen from the data analysis in Table 2, 

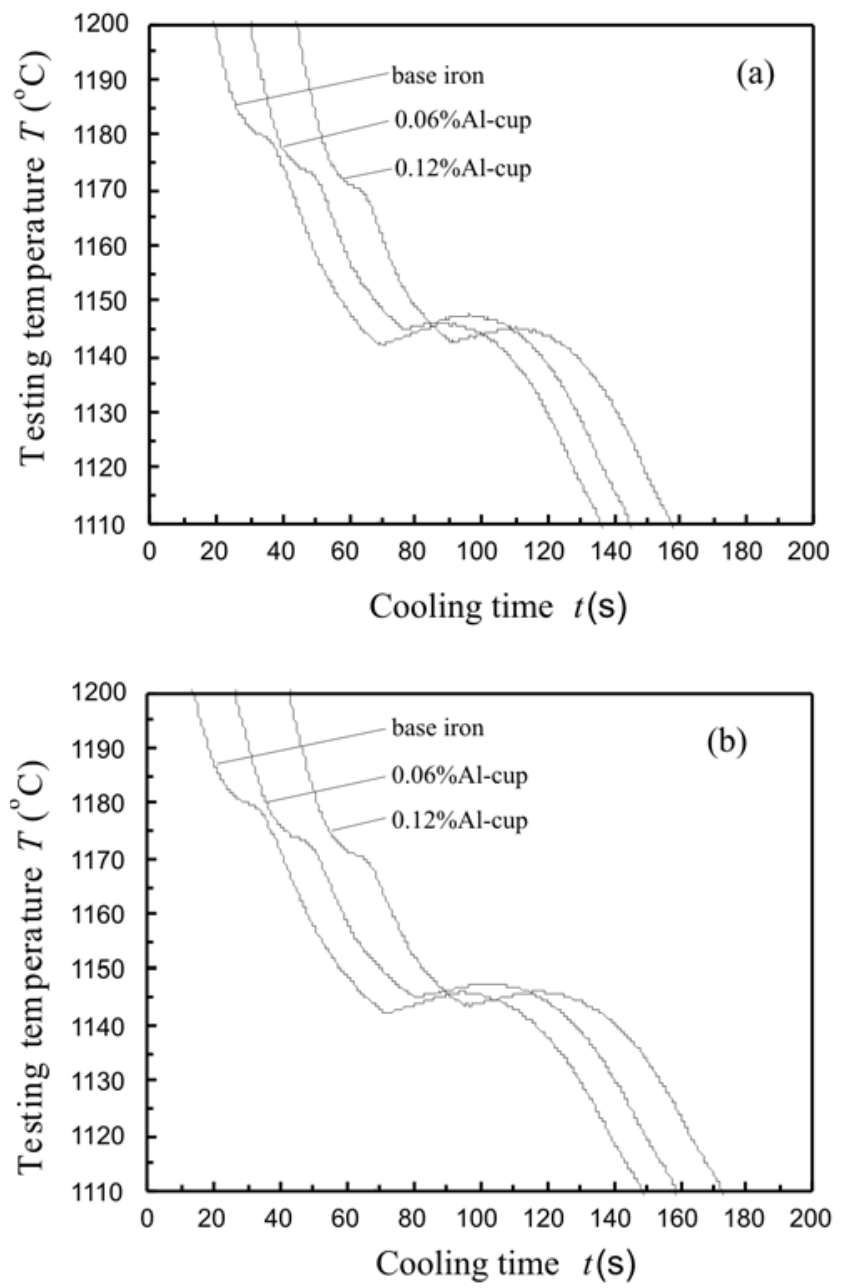

Fig. 4. Cooling curves of sulfur characteristic for base iron melt.

the increasing amount of sulfur has little effect on the primary crystal precipitation phase of the molten iron, liquidus temperature $T_{\mathrm{L}}$ and liquidus platform slope $\alpha_{\mathrm{L}}$ were equivalent in values before and after FeS alloyed treatment. After de-oxygenation, both of the two characteristic temperatures were significantly changed. The results further indicate that the effect of oxygen on the activity of carbon and silicon is larger than that of sulfur. On the contrary, the eutectic solidification zone fluctuated greatly with the change of sulfur content. As the sulfur content increased, eutectic recalescence temperature $R$ and oxygen factor $\mathrm{OXF}$ values were equivalent, and eutectic solidification enduring time $t_{\mathrm{E}}$ and minimum eutectic temperature $T_{\mathrm{EU}}$ both increased slightly at the same time. Proper de-oxygenation increases the rising amplitude, while excessive de-oxygenation can reduce it. This phenomenon indicates that sulfur promotes the development of graphite eutectic, and its function can be strengthened when oxygen content is

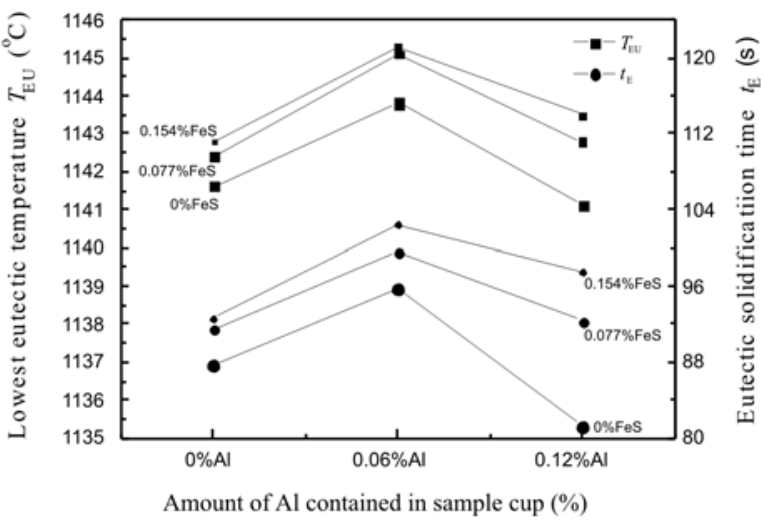

Fig. 5. Change of curves of characteristic parameters during eutectic solidification with different sulfur contents.

appropriate. However, when the amount of sulfur is overly increased, the potential growth of amplitude becomes limited, as increasing sulfur content consumes more nodularizing element $\mathrm{Mg}$ and causes slag defects. The variation curves of characteristic eutectic temperatures with sulfur content are shown in Fig. 5.

\section{Conclusions}

In this paper, the metallurgical behavior of oxygen and sulfur elements in base iron of ductile iron were studied by thermal analysis using a series of sample cups containing different active $\mathrm{Al}$ additives. The specific conclusions are as follows:

1. The change of oxidation degree has an observable influence on the characteristic parameters of the primary and eutectic phases in the cooling curve. Compared with the sulfur element, oxygen has a strong affinity with carbon and silicon and is the main metallurgical control factor of iron liquid. The effect of active oxygen on the initial crystal temperature $T_{\mathrm{L}}$ is more regular and related. Moreover, the de-oxygenation product's state during nodularization mainly affects the eutectic graphite crystallization. When the oxidization factor OXF is in the range of $20-30$, the molten iron nucleation is in its best condition.

2. Sulfur element affects the graphite nucleation and growth during eutectic solidification. However, the variation of the lowest eutectic temperature $T_{\mathrm{EU}}$ and eutectic solidification time $t_{\mathrm{E}}$ is complicated. The weaker chemistry characteristic of sulfur (compared to oxygen) leads to a slow desulfurization state during nodularization. Therefore, the aggregation coarsening of sulfide products is slow, and the direct antispherification of sulfur is weaker than that of oxygen from the perspective of chemical adsorption.

3. The experimental results show that oxygen is 
probably the most direct anti-spherification element. The relationship between sulfur and nodularization rate is complex and is greatly influenced by technological factors. The sulfide products play an auxiliary role in the nucleation of the oxidation product.

\section{Acknowledgement}

The authors gratefully acknowledge the financial support by the National Natural Science Foundation of China (Grant No. 51474082).

\section{References}

[1] Riebisch, M., Sönke, H. G., Pustal, B., Bührig-Polaczek, A.: Int. J. Metalcast., 12, 2018, p. 106. doi:10.1007/s40962-017-0146-7

[2] Pan, Y. N., Lin, H. T., Lin, C. C., Chang, R. M.: Production of Selected Key Ductile Iron Castings Used in Large-Scale Windmills. Cham, Springer 2015. doi:10.1007/978-3-319-48117-3_34

[3] Labrecque, C., Gagné, M.: Can. Metall. Q., 37, 1998, p. 343. doi:10.1016/S0008-4433(98)00031-7

[4] Cai, Q. Z., Wei, B. K.: China Foundry, 5, 2008, p. 82.

[5] Kusakawa, T.: Advanced Materials Research, 4-5, 1997, p. 61. doi:10.4028/www.scientific.net/AMR.4-5.61

[6] Santhosh, A. J., Lakshmanan, A. R.: China Foundry, 13, 2016, p. 352. doi:10.1007/s41230-016-5078-y

[7] Stan, S., Chisamera, M., Riposan, I., Barstow, M.: J. Therm. Anal. Calorim., 110, 2012, p. 1185. doi:10.1007/s10973-011-2128-y
[8] Mampaey, F.: International Journal of Cast Metals Research, 11, 1991, p. 307. doi:10.1080/13640461.1999.11819291

[9] Anjos, V.: Use of Thermal Analysis to Control the Solidification Morphology of Nodular Cast Irons and Reduce Feeding Needs. [Ph.D. Thesis]. Duisburg-Essen, University of Duisburg-Essen 2015.

[10] Li, D. Y., Xu, Z. Y., Ma, X. L., Wang, L. H.: J. Mech. Eng., 53, 2017, p. 55. doi:10.3901/JME.2017.20.054

[11] Xu, Z. Y., Li, D. Y., Ma, X. L., Wang, L. H.: J. Mech. Eng., 53, 2017, p. 37. doi:10.3901/JME.2017.22.037

[12] Mampaey, F., Habets, D., Seutens, F., Plessers, J.: Int. Foundry Res., 60, 2008, p. 2. doi:10.1007/BF03355464

[13] Hecht, M., Loury, J. B.: Fonderie, Fondeur d'aujourd; hui, 2040, 2001, p. 12.

[14] Elbel, T., Senberger, J., Zadera, A., Hampl, J.: Arch. Mater. Sci. Eng., 33, 2008, p. 111.

[15] Hampl, J., Elbel, T.: Arch. Foundry Eng., 10, 2010, p. 55 .

[16] Elbel, T., Senberger, J., Zadera, A., Vladik, R.: Arch. Mater. Sci. Eng., 28, 2007, p. 649.

[17] Ekengård, J., Diószegi, A., Jönsson, P. G.: In: Proceedings of the 10th International Symposium on the Science and Processing of Cast Iron. Mar del Plata, INTEMA 2015, p. 1. ISBN: 978-987-45833-0-7

[18] Chaudhari, M. D., Heine, R. W., Loper, C. R.: AFS Trans., 82, 1974, p. 431.

[19] Zhu, P., Smith, R. W.: AFS Trans., 103, 1995, p. 601.

[20] Li, Z. H., Li, Y. X.: Metall. Mater. Trans. A, 36, 2005, p. 2455. doi:10.1007/s11661-005-0119-y

[21] Stefanescu, D. M.: Int. J. Metalcast., 9, 2015, p. 7. doi:10.1007/BF03355598

[22] Chisamera, M., Riposan, I., Stan, S., Toboc, P., Skaland, T., White, D.: Int. J. Cast Metal. Res., 24, 2011, p. 28. doi:10.1179/136404610X12816241546618

[23] Li, D. Y., Shi, D. Q., Li, F., Zhang, Y. T., Dong, J. W.: China Foundry, 2, 2005, p. 34. 